\title{
Development of radiological and clinical evidence of parenchymal fibrosis in men with non-malignant asbestos-related pleural lesions
}

\author{
G H G MCMILLAN AND C E ROSSITER \\ From the Medical Research Unit, HM Naval Base, Devonport PLI 4RU, UK
}

ABSTRACT After assessment of radiographs taken in 1966, 201 men employed at HM Dockyard, Devonport, were judged to have pleural abnormalities due to exposure to asbestos but to be free from small opacities (ILO U/C 1971 category 1/1 or more), mesothelioma, or bronchial carcinoma. By 1976, 32 of these men had died. Of the survivors, 155 were re-examined to determine the attack rates of parenchymal fibrosis or malignant disease, or both. In 1976, $16(10 \cdot 3 \%)$ of the survivors had radiographs showing small opacities of category $1 / 1$ or more. When additional clinical criteria had to be satisfied before a diagnosis of parenchymal fibrosis was made the attack rate in the survivors was $4.5 \%$. These attack rates were substantially higher than those observed in a sample of men with no initial pleural abnormality but were unrelated to age, smoking habit, occupation, duration of exposure to asbestos, or type of pleural abnormality. The number of cases of malignant disease was too small to allow any reliable conclusions.

Many men employed in HM Dockyard, Devonport, before 1970 were exposed to asbestos dust ${ }^{1}$ and as a result have developed pleural or parenchymal lesions, or both. ${ }^{2}$ When these men are told of the radiographic finding they not infrequently ask if this increases their risk of developing asbestosis (parenchymal fibrosis) or malignancy. This study was undertaken to assist in assessing this risk.

Pleural plaques have been seen as objective indicators of previous exposure to asbestos ${ }^{34}$ and, while they are harmless in themselves, ${ }^{5}$ it has been recommended that those with that abnormality should be followed up closely. ${ }^{6-9}$ Hillerdal $^{5}$ contends that from a medical point of view only limited gains are to be expected by such follow-up. He has reported that most of the patients with pleural plaques whom he subjected to extensive lung function tests had early fibrosis with stiff lungs and reduced volumes, although they had no symptoms, and he concluded that there is often subclinical asbestosis in people with typical pleural plaques. In another dockyard population the incidence of bronchial carcinoma was twice as high in those with pleural plaques as in those without but with the same exposure. ${ }^{1011}$ There is no

Received 9 March 1979

Accepted 5 February 1981 evidence that men with pleural plaques have an excess incidence of mesothelioma.

Diffuse pleural thickening affecting the visceral pleura may occur with or without pleural plaques and, when extensive, can cause restrictive lung function changes. ${ }^{12}$ Sheers ${ }^{13}$ has described 52 cases where there has been an acute pleural reaction consisting of either an effusion or a striking increase in the extent of the pleural reaction within a short period. In 35 cases this has been the first indication of any asbestos-related disorder while the remainder occurred in previously recognised cases of diffuse pleural thickening. While it may be difficult initially to differentiate between the acute reaction and mesothelioma there is no firm evidence that either diffuse thickening or this reaction carry an excess risk of mesothelioma.

\section{Material and methods}

In 1970 a review was undertaken of the full-size posteroanterior chest radiographs and clinical records of all men who had been referred to the Medical Research Unit in Devonport Dockyard or to Plymouth General Hospital Chest Clinic with suspected asbestos-related pleural lesions, most of which had been detected during mass miniature 
radiography in the dockyard. Follow-up was started for those in whom the diagnosis had been confirmed. The survivors of those who had been exposed at work in the dockyard and examined in 1966 (when full protective measures were introduced) were recalled for radiographic and clinical examination in 1976, to determine the attack rates of parenchymal fibrosis, mesothelioma, and bronchial carcinoma over a 10-year period. For most of those who had died by 1976 there were records and radiographs made at routine examination within the year before death. Asbestos exposure was assessed from a detailed occupational history, ${ }^{14}$ but actual exposure measurements were not available.

The full-size posteroanterior chest radiographs taken in 1966 and 1976 were read independently, in random order, and without knowledge of date, to an extended version of the ILO U/C 1971 classification by three experienced readers (Drs G Sheers, J C Gilson, K P S Lumley). The extension of the 1971 classification required pleural changes to be differentiated into pleural plaques or diffuse pleural thickening.

In an attempt to reduce inter-reader variation a selection of full-size chest radiographs from other surveys of the dockyard population, which were considered to exhibit the complete range of asbestosrelated lesions, other pathologies, or no abnormalities, was presented to the three readers in committee, and they were required to agree on the ILO U/C classification of each radiograph. These radiographs could not be distinguished from the survey films and were mixed randomly in the ratio 1:7 in each batch of films during the independent reading. Each reader's clerk could identify the "trigger films" from the reading sheet and after the reader had dictated his classification he was presented with the agreed classification for comparison.

For every aspect of radiographic abnormality the agreed reading of at least two of the three readers has been used in the tabulations. Small irregular opacities were considered to be present when this reading was category $1 / 1$ or more. The agreed reading of the 1966 radiographs showed asbestosrelated pleural lesions without co-existing small opacities, mesothelioma, or carcinoma in 201 cases. These men are the subjects of this report. The classification of the 1966 radiograph was used to allocate each of these men to one of four categories of pleural abnormality; uncalcified pleural plaques, calcified pleural plaques, diffuse pleural thickening, or diffuse thickening with plaques. The difference between that film and the follow-up film thus allowed assessment of the development of new lesions in relation to the pre-existing pleural lesions.

\section{Results}

Altogether 169 of the 201 men were alive in 1976, and $155(92 \%)$ attended for examination. Nine refused to attend, two had moved away, and three were ill (not chest disease). Of the 32 men who had died, 20 had had a follow-up radiograph and examination within the 12 months before their death. Data on these 175 men (155 living, 20 dead) have been combined in several of the tabulations. Separate tabulations for the living and dead show similar results. The percentage of men re-assessed (table 1) ranged from $69 \%$ of those who had diffuse pleural thickening to $96 \%$ who had calcified plaques. All the responders were clinically examined $(80 \%$ GHGM, $20 \%$ GS*): 134 had lung function tests $\left(\mathrm{FEV}_{1}, \mathrm{FVC}, \mathrm{RV}, \mathrm{TLC}\right.$, and gas transfer factor) immediately after examination. The remaining 21 refused further examination, either in whole or in part, and results of lung function tests performed in the previous year or so were used.

Among the responders those who had had uncalcified plaques in 1966 were on average six years younger than those with calcified plaques and three years younger than those with diffuse pleural thickening at that time. As might be expected, those who had died by 1976 were the older men born about

*G Sheers, Plymouth General Hospital.

Table 1 Men in study population related to 1966 pleural abnormality

\begin{tabular}{|c|c|c|c|c|c|}
\hline & \multirow{2}{*}{$\begin{array}{l}\text { No } \\
\text { of men }\end{array}$} & \multicolumn{4}{|c|}{966 pleural abnormality } \\
\hline & & $\begin{array}{l}\text { Uncalcified pleural } \\
\text { plaques }\end{array}$ & Calcified plaques & Diffuse thickening & $\begin{array}{l}\text { Diffuse thickening } \\
\text { and plaques }\end{array}$ \\
\hline Total No of men & 201 & 133 & 27 & 13 & 28 \\
\hline Re-examined in 1976 & $155(77 \%)$ & $107(80 \%)$ & $22(81 \%)$ & $8(62 \%)$ & $18(64 \%)$ \\
\hline Dead with predeath examination & $20(10 \%)$ & $10(8 \%)$ & $4(15 \%)$ & $1(8 \%)$ & $5(18 \%)$ \\
\hline Total included in analysis & $175(87 \%)$ & $117(88 \%)$ & $26(96 \%)$ & $9(69 \%)$ & $23(82 \%)$ \\
\hline Death with no predeath examination & 12 & 5 & - & 3 & 4 \\
\hline \multicolumn{6}{|l|}{ Non-responders } \\
\hline III & 3 & 3 & - & - & - \\
\hline Moved away & 2 & 1 & 1 & - & - \\
\hline Refused & 9 & 7 & 一 & 1 & 1 \\
\hline
\end{tabular}


Table 2 Inter-reader variation on ILO/UC classification of follow-up radiographs

\begin{tabular}{|c|c|c|c|c|}
\hline \multirow[t]{2}{*}{ Abnormality } & \multicolumn{3}{|c|}{ Reader } & \multirow[t]{2}{*}{$C h i^{2}$} \\
\hline & 1 & 2 & 3 & \\
\hline \multicolumn{5}{|c|}{ Uncalcified pleural plaques } \\
\hline Present & 116 & 129 & 127 & 3.95 \\
\hline Absent & 39 & 26 & 28 & \\
\hline \multicolumn{5}{|c|}{ Calcified pleural plaques } \\
\hline Present & 65 & 62 & 58 & 0.66 \\
\hline Absent & 90 & 93 & 97 & \\
\hline \multicolumn{5}{|c|}{ Diffuse pleural thickening } \\
\hline Present & 39 & 39 & 46 & $1 \cdot 08$ \\
\hline Absent & 116 & 116 & 109 & \\
\hline \multicolumn{5}{|c|}{ Small opacities $1 / 1$ or more } \\
\hline Present & 10 & 45 & 18 & $32 \cdot 79 *$ \\
\hline Absent & 145 & 110 & 137 & \\
\hline
\end{tabular}

*p $<0.01$.

10 years before the survivors, but the relationship between age and pleural abnormality was similar to that seen in the survivors. On average those with diffuse thickening and no plaques in 1966 had a shorter period in occupations with potential exposure to asbestos dust and shorter time since that period began than those with plaques alone or together with diffuse thickening. There were no significant differences in smoking habits between the pleural abnormality groups.

The 1976 radiographs were used to assess interreader variation as the 1966 radiographs were the basis of selection of the subjects and by definition included none showing small opacities $1 / 1$ or more. There was no significant variation with respect to pleural abnormalities but, despite the use of trigger films and the long experience of the readers, reader 2 read significantly more cases of small opacities $1 / 1$ or more (table 2). This variation has caused us to use the agreed reading of at least two readers for every aspect of radiographic abnormality. All readers considered all films to be of acceptable quality.

Of the 175 men, $23(13.1 \%)$ attained a classification of small opacities category $1 / 1$ or more by 1976 or their death (16 survivors, 7 dead). This is related to the 1966 radiographic classification and mean age, mean duration of exposure, and time since that started, and smoking history (tables 3-7). Fifteen $(12.8 \%)$, ten living and five dead, of the 117 with simple plaques in 1966 developed small opacities $1 / 1$ or more, giving attack rates of $9.3 \%$ in the living in a 10 -year period and $50 \%$ in the dead followed on average for five years. They were slightly older than those who did not develop small opacities, and their duration of exposure and time since exposure started were similarly slightly longer. The six $(23.1 \%)$, four living and two dead, of 26 with calcified plaques who developed small opacities were also slightly older than those who did not, and their exposure duration and time since that started were also slightly longer.

Based on the other three pleural abnormality groups, one man with diffuse thickening only would have been expected to have developed small opacities. In fact none did, but no firm conclusions can be drawn from this as there were only nine men in that

Table 3 Number of men in each radiographic classification in 1966 and in 1976

\begin{tabular}{|c|c|c|c|c|c|c|c|c|c|c|c|}
\hline \multirow{3}{*}{$\begin{array}{l}1966 \\
\text { radiographic: } \\
\text { classification }\end{array}$} & \multicolumn{11}{|c|}{1976 radiographic classification } \\
\hline & \multicolumn{6}{|c|}{ Without small opacities $1 / 1$ or more } & \multicolumn{5}{|c|}{ With small opacities $1 / 1$ or more } \\
\hline & Nil & $U C P$ & $C P$ & $D T$ & $D T P$ & $\begin{array}{l}A l l \\
(n=152)\end{array}$ & $U C P$ & $C P$ & $D T$ & $D T P$ & $\begin{array}{l}A l l \\
(n=23)\end{array}$ \\
\hline $\begin{array}{l}\text { UCP } \\
\text { CP } \\
\text { DT } \\
\text { DTP }\end{array}$ & 2 & $\begin{array}{r}65 \\
1 \\
2\end{array}$ & $\begin{array}{r}17 \\
11 \\
1\end{array}$ & $\begin{array}{l}3 \\
1 \\
4\end{array}$ & $\begin{array}{r}15 \\
9 \\
7 \\
14\end{array}$ & $\begin{array}{r}102 \\
20 \\
9 \\
21\end{array}$ & 8 & $\begin{array}{l}3 \\
4 \\
1\end{array}$ & 1 & $\begin{array}{l}4 \\
2\end{array}$ & $\begin{array}{r}15 \\
6 \\
0 \\
2\end{array}$ \\
\hline
\end{tabular}

UCP = Uncalcified plaque. $\quad$ DT $=$ Diffuse pleural thickening.

$C P=$ Calcified plaque. $\quad$ DTP $=$ Diffuse pleural thickening and plaques (uncalcified or calcified).

Table 4 Mean age (years) in 1966 of men in each radiographic classification in 1966 and in 1976

\begin{tabular}{|c|c|c|c|c|c|c|c|c|c|c|c|}
\hline \multirow{3}{*}{$\begin{array}{l}1966 \\
\text { radiographic } \\
\text { classification }\end{array}$} & \multicolumn{11}{|c|}{1976 radiographic classification } \\
\hline & \multicolumn{6}{|c|}{ Without small opacities $1 / 1$ or more } & \multicolumn{5}{|c|}{ With small opacities $1 / 1$ or more } \\
\hline & Nil & $U C P$ & $C P$ & $D T$ & $D T P$ & $\begin{array}{l}A l l \\
(n=50)\end{array}$ & $U C P$ & $C P$ & $D T$ & $D T P$ & $\begin{array}{l}A l l \\
(n=53)\end{array}$ \\
\hline $\begin{array}{l}\text { UCP } \\
\text { CP } \\
\text { DT } \\
\text { DTP }\end{array}$ & 46 & $\begin{array}{l}48 \\
47 \\
51\end{array}$ & $\begin{array}{l}43 \\
53 \\
61\end{array}$ & $\begin{array}{l}52 \\
57 \\
54\end{array}$ & $\begin{array}{l}59 \\
54 \\
50 \\
54\end{array}$ & $\begin{array}{l}49 \\
54 \\
51 \\
54\end{array}$ & 49 & $\begin{array}{l}51 \\
59 \\
\\
38\end{array}$ & 54 & $\begin{array}{l}57 \\
67\end{array}$ & $\begin{array}{l}51 \\
62 \\
46\end{array}$ \\
\hline
\end{tabular}


Table 5 Mean duration of exposure to asbestos (years) up to 1966 of men in each radiographic classification in 1966 and in 1976

\begin{tabular}{|c|c|c|c|c|c|c|c|c|c|c|c|}
\hline \multirow{3}{*}{$\begin{array}{l}1966 \\
\text { radiographic } \\
\text { classification }\end{array}$} & \multicolumn{11}{|c|}{1976 radiographic classification } \\
\hline & \multicolumn{6}{|c|}{ Without small opacities $1 / 1$ or more } & \multicolumn{5}{|c|}{ With small opacities $1 / 1$ or more } \\
\hline & Nil & $U C P$ & $C P$ & $D T$ & $D T P$ & $\begin{array}{l}\text { All } \\
(n=20)\end{array}$ & UCP & $C P$ & $D T$ & $D T P$ & $\begin{array}{l}\text { All } \\
(n=24)\end{array}$ \\
\hline $\begin{array}{l}\text { UCP } \\
\text { CP } \\
\text { DT }\end{array}$ & 21 & $\begin{array}{l}19 \\
<1\end{array}$ & $\begin{array}{l}19 \\
24\end{array}$ & $\begin{array}{l}17 \\
12\end{array}$ & $\begin{array}{l}21 \\
23 \\
11\end{array}$ & $\begin{array}{l}19 \\
23 \\
10\end{array}$ & 23 & $\begin{array}{l}20 \\
26\end{array}$ & & $\begin{array}{l}23 \\
32\end{array}$ & $\begin{array}{l}22 \\
28\end{array}$ \\
\hline DTP & & 17 & 27 & 23 & 29 & 27 & & 20 & 36 & & 28 \\
\hline
\end{tabular}

Table 6 Mean time up to 1966 since first exposure to asbestos (years) of men in each radiographic classification in 1966 and in 1976

\begin{tabular}{|c|c|c|c|c|c|c|c|c|c|c|c|}
\hline \multirow{2}{*}{$\begin{array}{l}1966 \\
\text { radiographic } \\
\text { classification }\end{array}$} & \multicolumn{11}{|c|}{1976 radiographic classification } \\
\hline & \multicolumn{6}{|c|}{ Without small opacities $1 / 1$ or more } & \multicolumn{5}{|c|}{ With small opacities $1 / 1$ or more } \\
\hline $\begin{array}{l}\text { UCP } \\
\text { CP } \\
\text { DT } \\
\text { DTP }\end{array}$ & 26 & $\begin{array}{l}25 \\
27 \\
31\end{array}$ & $\begin{array}{l}22 \\
28 \\
27\end{array}$ & $\begin{array}{l}27 \\
13 \\
28\end{array}$ & $\begin{array}{l}25 \\
30 \\
17 \\
32\end{array}$ & $\begin{array}{l}25 \\
29 \\
18 \\
31\end{array}$ & 25 & $\begin{array}{l}32 \\
27 \\
\\
20\end{array}$ & 36 & $\begin{array}{l}24 \\
39\end{array}$ & $\begin{array}{l}26 \\
\frac{31}{28}\end{array}$ \\
\hline
\end{tabular}

Table 7 Smoking habits of men in each radiographic classification in 1966 and in 1976

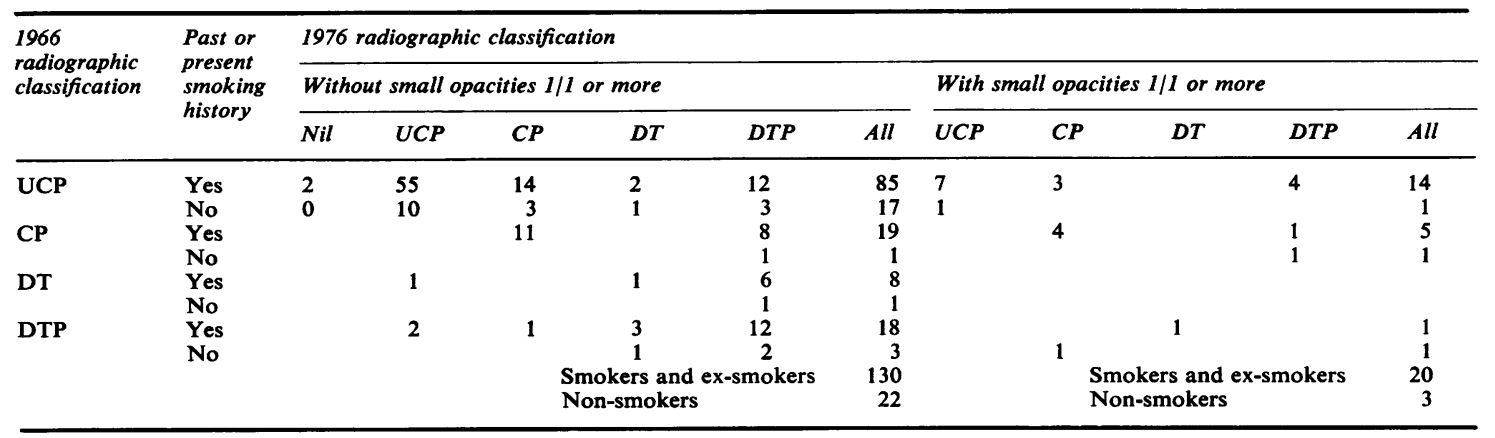

group. Two $(8 \cdot 7 \%)$ of the 23 with diffuse thickening and plaques did develop small opacities. They were both alive in 1976 and were a little younger than those who had not so progressed, but their durations of exposure and time since first exposure were similar. Two men considered to show uncalcified plaques on the 1966 radiograph had no pleural lesions recorded on the reading of the 1976 radiograph.

Twenty $(87 \%)$ of the 23 who developed small opacities had a positive history of tobacco smoking compared with $85 \%$ of the 152 who did not. This small difference was not statistically significant. The proportion of men in each smoking category (smoker, ex-smoker, and non-smoker) was similar to that found in other surveys of dockyard employees. ${ }^{21415}$ There was no evidence in this group of men of any consistent relationship between smoking habit and development of small opacities.

The 155 men who were still alive in 1976 were allocated to an exposure group on the basis of their occupational history (table 8). Those in group 1 were in occupations with the greatest risk of exposure to asbestos dust and those in group 3 the lowest risk. The incidence of small opacities was $5.5 \%$ in group 1 , $9.1 \%$ in group 2 , and $15.8 \%$ in group 3 .

Data from the independent radiograph reading were combined with clinical and lung function findings in such a way that men with a 1976 film in which at least two readers agreed on the presence of small opacities $1 / 1$ or more, persistent basal crackles, and a reduction in gas transfer factor below $75 \%$ of predicted value in the absence of significant airway 
Table 8 Comparisons of attack rates of small opacities category 1/1 or more, clinically confirmed, parenchymal fibrosis, smoking habits, and duration of potential exposure in men with pleural lesions in 1966, group A (this paper -survivors only) and with no pleural lesions in 1966, group B (McMillian et al ${ }^{14}$ )

\begin{tabular}{|c|c|c|c|c|c|c|c|c|c|c|}
\hline \multirow[t]{2}{*}{$\begin{array}{l}\text { Exposure } \\
\text { group }\end{array}$} & \multirow[t]{2}{*}{ Occupations } & \multirow[t]{2}{*}{ Group } & \multirow[t]{2}{*}{$\begin{array}{l}\text { No } \\
\text { followed-up }\end{array}$} & \multicolumn{3}{|c|}{$\begin{array}{l}\% \text { in each smoking } \\
\text { category }\end{array}$} & \multirow{2}{*}{$\begin{array}{l}\text { Mean duration } \\
\text { (y) of } \\
\text { occupational } \\
\text { exposure }\end{array}$} & \multirow{2}{*}{$\begin{array}{l}\%(N o) \text { with } \\
\text { SO* } 1 / 1 \text { or } \\
\text { more }\end{array}$} & \multirow{2}{*}{$\begin{array}{l}\%(N o) \text { with } \\
\text { SO* I/I or } \\
\text { more, signs, } \\
\text { and LFT } \\
\text { changes of } \\
\text { parenchymal } \\
\text { fibrosis }\end{array}$} & \multirow{2}{*}{$\begin{array}{l}\%(N o) \text { with } \\
\text { clinical and } \\
\text { radiographic } \\
\text { diagnosis of } \\
\text { parenchymal } \\
\text { fibrosis }\end{array}$} \\
\hline & & & & $S$ & $E x-S$ & Non-S & & & & \\
\hline 1 & $\begin{array}{l}\text { Lagger, asbestos } \\
\text { sprayer, sailmaker, } \\
\text { lagger, asbestos } \\
\text { storeman, painter } \\
\text { afloat }\end{array}$ & $\begin{array}{c}\text { A } \\
\mathbf{B}\end{array}$ & $\begin{array}{l}18 \\
29\end{array}$ & $\begin{array}{l}61 \\
41\end{array}$ & $\begin{array}{l}22 \\
41\end{array}$ & $\begin{array}{l}17 \\
17\end{array}$ & $\begin{array}{l}20 \cdot 5 \\
18 \cdot 5\end{array}$ & $5 \cdot 5(1)$ & $5 \cdot 5(1)$ & $3 \cdot 4(1)$ \\
\hline 2 & $\begin{array}{l}\text { Electrical fitter, } \\
\text { caulker, riveter, } \\
\text { coppersmith, ship } \\
\text { fitter, boilermaker, } \\
\text { driller, welder, } \\
\text { burner, joiner, } \\
\text { plumber, ship- } \\
\text { wright, } \\
\text { mechanical fitter }\end{array}$ & $\begin{array}{l}\mathbf{A} \\
\mathbf{B}\end{array}$ & $\begin{array}{r}99 \\
607\end{array}$ & $\begin{array}{l}47 \\
44\end{array}$ & $\begin{array}{l}36 \\
29\end{array}$ & $\begin{array}{l}17 \\
27\end{array}$ & $\begin{array}{l}22 \cdot 0 \\
18 \cdot 3\end{array}$ & $\begin{array}{c}9 \cdot 1 \quad(9) \\
\end{array}$ & $3 \cdot 0$ & $0.5(3)$ \\
\hline 3 & $\begin{array}{l}\text { All other } \\
\text { occupations in } \\
\text { dockyard }\end{array}$ & $\begin{array}{l}\text { A } \\
\mathbf{B}\end{array}$ & $\begin{array}{r}38 \\
335\end{array}$ & $\begin{array}{l}58 \\
56\end{array}$ & $\begin{array}{l}39 \\
29\end{array}$ & $\begin{array}{r}3 \\
15\end{array}$ & $\begin{array}{l}20 \cdot 8 \\
17 \cdot 6\end{array}$ & $15 \cdot 8 \quad(6)$ & $8 \cdot 0(3)$ & $0.6(2)$ \\
\hline $1-3$ & All occupations & $\begin{array}{l}\mathbf{A} \\
\mathbf{B}\end{array}$ & $\begin{array}{l}155 \\
971\end{array}$ & $\begin{array}{l}51 \\
48\end{array}$ & $\begin{array}{l}35 \\
29\end{array}$ & $\begin{array}{l}14 \\
22\end{array}$ & $\begin{array}{l}21 \cdot 5 \\
17 \cdot 8\end{array}$ & $10 \cdot 3(16)$ & $4 \cdot 5(7)$ & $0 \cdot 6(6)$ \\
\hline
\end{tabular}

SO = Small opacities.

LFT = Lung function tests.

obstruction were considered to have definite evidence of asbestos-induced parenchymal fibrosis. Seven $(4.5 \%)$ of the 155 responders satisfied these strict criteria; one in group 1, three in group 2, and three in group 3.

No cases of mesothelioma nor of bronchial carcinoma were found among the responders. Three of the dead had mesothelioma ( 2 pleural, 1 peritoneal) and another died from bronchial carcinoma. That man and one of those with pleural mesothelioma also had small opacities $1 / 1$ or more and have been included in relevant tables.

\section{Discussion and conclusions}

The radiological data suggest that some $13 \%$ of men in Devonport Dockyard who have had sufficient exposure to asbestos dust and time since that exposure to have developed pleural changes (but not small opacities of category 1/1) can be expected subsequently to develop small opacities category $1 / 1$ or more within 10 years of identification of the pleural lesion. The type of pleural lesion, time since first exposure, occupation, age, and smoking habit do not appear to be the factors that determine which of the men will be affected.

The relatively low attack rate in group 1 , men with the heaviest exposure who have shown the highest prevalence of parenchymal fibrosis in previous studies of random samples of the dockyard popula- tion $^{2} 1415$ is explained by the method of selecting men for this study: many men in group 1 had developed small opacities category $1 / 1$ or more by 1966 and thus were excluded. The attack rate of clinically confirmed parenchymal fibrosis of $4.5 \%$ is in sharp contrast to that in responders in a large random sample of men drawn from the same dockyard population $^{14}$ and who had neither pleural nor parenchymal lesion in 1966 (table 8). In 1977 these latter men were examined by the same physicians as the present study group. Data from that study have been reviewed in the light of the slightly different lung-function criteria applied to the $155 \mathrm{men}$, and the attack rate of $0.6 \%$ is confirmed. This strengthens but does not confirm our opinion that men with pleural lesions are more likely to develop parenchymal fibrosis than their similarly employed colleagues with no pleural lesions. Our caution is based on important differences between the two groups of men (table 8). When the groups were divided by occupation, an indicator of severity of exposure, there were relatively more men from the 155 men with pleural lesions in the heaviest exposure (group 1) and fewer in the lightest exposure (group 3). Overall there were relatively more non-smokers in the larger sample, and their mean duration of exposure was about four years shorter. Nevertheless, the relative number of men and smokers were similar in exposure group 2, but the attack rates were very dissimilar (log likelihood ratio $4.43-p=0.036$ ). Furthermore, 
100-mm radiographs were used to screen the larger sample and determine which men required further examination by full size radiograph. Although a very low threshold of suspicion was maintained when examining the smaller films it is likely that some cases of small opacities were missed ${ }^{16}$ though unlikely that these included any of classification $1 / 1$ or more. The attack rates for group 3 are also very dissimilar ( $\log$ likelihood ratio $=7 \cdot 52, \mathrm{p}=0.006)$.

Since $10.3 \%$ of the men who were re-examined had developed small opacities ten years later $(13 \cdot 1 \%$, if those who had died are included) we concluded that asbestos-related pleural lesions may not be merely "markers" of previous exposure to asbestos but may identify those at greatest risk of developing parenchymal fibrosis. The number of cases of mesothelioma (3) and of bronchial carcinoma (1) is too small to establish a relationship with benign pleural lesions.

We gratefully acknowledge the co-operation of our subjects and the work of the staff at the Medical Research Unit and Beaumont House Chest Clinic, Plymouth, especially that of our colleagues who read the radiographs.

\section{References}

${ }^{1}$ Harries PG. $R N$ clinical research working party report $I / 7 I$. Alverstoke, Gosport, Hants: Institute of Naval Medicine, 1971.

${ }^{2}$ Harries PG, Rossiter CE, Coles RM. Clinical research working party report 1/76. Alverstoke, Gosport, Hants: Institute of Naval Medicine, 1976.
${ }^{3}$ Becklake MR. State of the art. Asbestos-related diseases of the lung and other organs: their epidemiology and implications for clinical practice. Am Rev Respir Dis 1976;114:187-227.

${ }^{4}$ Hillerdal G. Pleural plaques in a health survey material. Frequency, development and exposure to asbestos. Scand J Respir Dis 1978;59:257-63.

${ }^{5}$ Hillerdal G. Pleural plaques. Occurrence, exposure to asbestos and clinical importance. Uppsala: Uppsala University, 1980. (Doctoral thesis.)

${ }^{6}$ Kendall B, Caplin M. Pleural calcification. Br J Dis Chest $1967 ; 61: 126-30$.

${ }^{7}$ Sargent EN, Jacobson G, Gordonson JS. Pleural plaques: a signpost of asbestos inhalation. Semin Roentgenol $1977 ; 12: 287-97$

${ }^{8}$ Moigneteau C, Touzeau PY, Guillement JM. Calcifications pleurales asbestosiques et pathologie associée (étude des 32 observations). Pneumon Coeur 1977;33:101-7.

9 Anderson HA, Selikoff IJ. Pleural reactions to environmental agents. Fed Proc 1978;37:2496-500.

${ }^{10}$ Fletcher DE. A mortality study of shipyard workers with pleural plaques. Br J Ind Med 1972;29:142-5.

${ }^{11}$ Edge JR. Asbestos-related disease in Barrow-in-Furness. Environ Res 1976;11:244-7.

12 Lumley KPS. Physiological changes in asbestos pleural disease. In: Walton WH, ed. Inhaled Particles IV, Proceedings of International Symposium. Oxford and New York: Pergamon Press, 1977:781-7.

13 Sheers G. Asbestos associated disease in employees in Devonport Dockyard. Ann NY Acad Sci 1979;330:2818.

14 McMillan GHG, Sheers G, Pethybridge RJ. A radiological follow-up study of the effects of asbestos in dockyard workers in Devonport. J R Nav Med Ser 1978;LXIV: 88-104.

${ }^{15}$ Sheers G, Templeton AR. Effects of asbestos in dockyard workers. Br Med J 1968;iii:574-9.

${ }^{16}$ Sheers G, Rossiter CE, Gilson JC, Mackenzie FAF. UK naval dockyards asbestos study. Br J Ind Med 1978;35: 195-203. 